\title{
Transcriptional control of IFNT expression
}

\author{
Toshihiko Ezashi ${ }^{1}$ and Kazuhiko Imakawa ${ }^{2}$ \\ ${ }^{1}$ Bond Life Sciences Center and Division of Animal Sciences, University of Missouri, Columbia, Missouri, USA and \\ ${ }^{2}$ Laboratory of Animal Breeding, Veterinary Medical Sciences and Animal Resource Science Center, Graduate \\ School of Agricultural and Life Sciences, The University of Tokyo, Tokyo, Japan
}

Correspondence should be addressed to T Ezashi; Email: ezashit@missouri.edu

\begin{abstract}
Once interferon-tau (IFNT) had been identified as a type I IFN in sheep and cattle and its functions were characterized, numerous studies were conducted to elucidate the transcriptional regulation of this gene family. Transfection studies performed largely with human choriocarcinoma cell lines identified regulatory regions of the IFNT gene that appeared responsible for trophoblast-specific expression. The key finding was the recognition that the transcription factor ETS2 bound to a proximal region within the 5' UTR of a bovine IFNT and acted as a strong transactivator. Soon after other transcription factors were identified as cooperative partners. The ETS2-binding site and the nearby AP1 site enable response to intracellular signaling from maternal uterine factors. The AP1 site also serves as a GATA-binding site in one of the bovine IFNT genes. The homeobox-containing transcription factor, DLX3, augments IFNT expression combinatorially with ETS2. CDX2 has also been identified as transactivator that binds to a separate site upstream of the main ETS2 enhancer site. CDX2 participates in IFNT epigenetic regulation by modifying histone acetylation status of the gene. The IFNT downregulation at the time of the conceptus attachment to the uterine endometrium appears correlated with the increased EOMES expression and the loss of other transcription coactivators. Altogether, the studies of transcriptional control of IFNT have provided mechanistic evidence of the regulatory framework of trophoblast-specific expression and critical expression pattern for maternal recognition of pregnancy.

Reproduction (2017) 154 F21-F31
\end{abstract}

\section{Introduction}

The function of the proteins that we now recognize as IFNT was established before their primary structures were known. The cloning and sequencing of the cDNAs reported thirty years ago caused considerable surprise, because type I IFN, which include the related IFNA and IFNB families, had always been assumed to be antiviral agents, expressed for a brief time in response to a viral infection and then secreted in order to stimulate viral resistance in target cells elsewhere in the body. What makes the IFNT unique, however, is not their ability to extend estrous cycle length in ruminants, since IFNA can accomplish this quite effectively (Green et al. 2005). Nor do the IFNT demonstrate reduced antiviral activity compared to their relatives; quite the opposite, they are quite potent in this respect and bind to the same receptors as all other type I IFNT. Instead, the uniqueness of the IFNT lies in their transcriptional control, which provides trophoblast-specific, timespecific, constitutive expression in the absence of a viral challenge. Additionally, production of IFNT is exceptionally high over the few days. As pointed out in the accompanying chapter of Ealy and coworkers (Ealy \& Woolridge 2017), the relatively recent evolution of the IFNT genes required the acquisition of distinctive regulatory sequences upstream of their transcription start sites. Although the topic of transcriptional control of IFNT expression has been reviewed previously (Roberts 2007, Roberts et al. 2008, Ealy \& Yang 2009), the review presented here is more comprehensive than the earlier ones. Our goal herein is to update the reader with the most recent literature on the topic and to attempt to resolve some conflicting results.

\section{Different transcriptional control of IFNT from other type I interferon family genes}

IFNT is a member of the type I interferon family that is expressed exclusively in trophectoderm in the early stage of trophoblast development (Farin et al. 1990) in the suborder Ruminantia (Leaman \& Roberts 1992, Roberts et al. 1992, Liu et al. 1996). As pointed out in the previous section, expression of IFNT is not inducible by viral infection but is sustained constitutively at high levels over several days during the preimplantation period (Cross \& Roberts 1991, Roberts 2007). Additionally, the signaling pathways and transcriptional activators that promote the upregulation of other type I gene families, such as IFNA and IFNB, are not involved

This paper is part of an Anniversary Issue celebrating 30 Years of Interferon-Tau. The Guest Editor for this section was Professor R Michael Roberts. 
in the regulatory control of the IFNT (Leaman et al. 1994). The realization that the transcriptional regulation of IFNT genes is distinct from that of other type I IFN genes (Roberts et al. 1992, Flint et al. 1994) represented an obvious challenge to those in the field.

Initial studies utilized up to $-1675 \mathrm{bp}$ (originally referred BTP-1.8 (Cross \& Roberts 1991) of the 5'-regulatory region of bovine IFNT1A gene, which was placed into a reporter plasmid (Cross \& Roberts 1991, Leaman et al. 1994). JAr cells became the cell line of choice to study transcriptional control because fast-growing ovine trophoblast lines were not available. It was also reasoned that trophoblast cells, like JAr, despite their human origin might express much of the basic transcriptional machinery that would permit IFNT regulatory region to be active. Truncation of the longer BTP-1.8 construct quickly revealed that regions within $450 \mathrm{bp}$ from the transcriptional start site allowed constitutive expression. The finding is consistent with the observation that the more proximal regions of the bovine and ovine IFNT genes are highly conserved (Leaman \& Roberts 1992). So-called 'mobility-shift electrophoresis' or 'gel-shift' experiments performed with crude nuclear extracts prepared from ovine conceptuses during the period of IFNT expression revealed a strong interaction of nuclear protein interaction with two regions, a proximal ( -91 to $-69 \mathrm{bp}$ from the transcriptional start site) and a more distal site ( -358 to $-322 \mathrm{bp}$ ) (Leaman et al. 1994). These were assumed to represent major sites of transcriptional control. Such interactions were not observed with extracts form older conceptuses that were not expressing IFNT at the time they were recovered. These gel-shift experiments provided a useful beginning to subsequent transcriptional control studies as they mirrored IFNT expression over time and implicated particular control regions likely to interact with transcription factors.

\section{Transcription factors regulating IFNT expression}

\section{Regulatory mechanisms that upregulate IFNT gene expression}

\section{ETS2 enhancer region}

To identify the factor(s) responsible for IFNT gene transcription, the proximal protein-binding region was employed as the bait sequence for a yeast one-hybrid screening with a day 13 ovine conceptus cDNA library, from which the transcription factor ETS2 was identified (Ezashi et al. 1998). ETS2 is a member of the ETS family of transcription factors that share a conserved ETS DNAbinding domain that recognizes a specific binding motif centered on a GGAA core. Active IFNT genes contain an ETS-binding site in the proximal site, whereas several ovine IFNT genes that are poorly expressed and could be 'pseudogenes' contain a mutated core motif
(TGAA) in the proximal binding site (Ezashi et al. 1998, Matsuda-Minehata et al. 2005). Overexpression of ETS2 strongly transactivated an IFNT reporter, while specific mutation of the ETS2-binding sequence substantially reduced both the basal and induced activity in the JAr cells (Ezashi et al. 2001, 2008, Ezashi \& Roberts 2004, Das et al. 2008). When a 6 bp CAGGAA ETS2 core binding sequence (Fig. 1C) was inserted into the equivalent region of the pseudogenes, the reporter still failed to confer higher ovine IFNT expression or induction with ETS2 overexpression. However, if the replacement nucleotide cassette was extended to $22 \mathrm{bp}$ on both ends from the ETS2 site and included

\section{A ETS AP1 \\ PLAU A GGAAATGAGGTCA \\ IFNT A GGAAGTGAGAGAG}
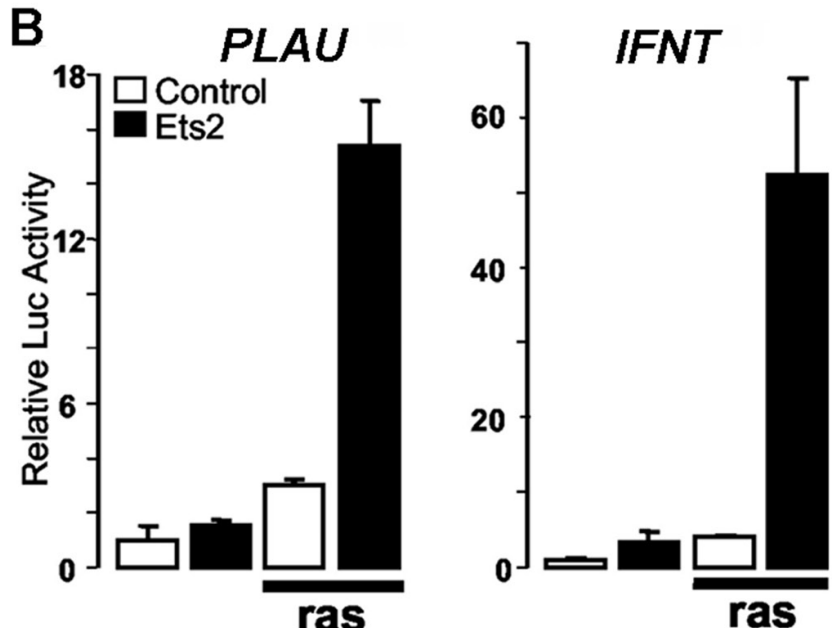

C

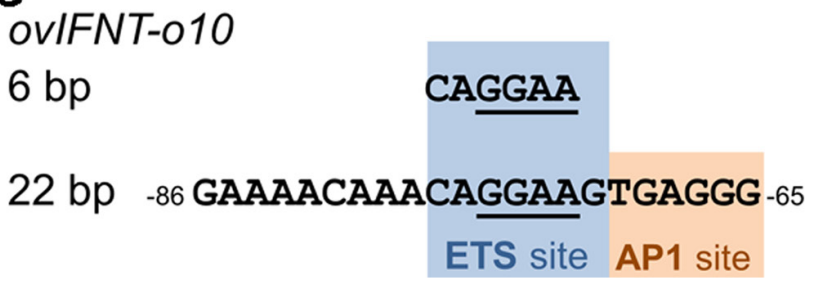

Figure 1 (A) Sequences of the ETS/AP1-binding sites of the murine PLAU and bovine IFNT1A control regions. The ETS core binding sequences are boxed. Conserved AP1-binding site is underlined. (B) Transcriptional activities of the PLAU and IFNT reporters by cotransfected ETS2 and HRAS expression plasmids (alone or in combination) into 3T3 cells. (A) and (B) are modified from Ezashi and Roberts (2004). (C) The 6 bp and 22 bp sequences of ETS-binding site of ovine IFNT-o10 (ovIFNT-o10) used in a study of Matsuda-Minehata et al. (2005). The nonfunctional $6 \mathrm{bp}$ contains only the core of ETS-binding site. The functional 22 bp has both ETS (blue) and adjacent AP1-binding site (orange). 
an adjacent putative AP1 site from active ovine IFNT (ovIFNT-o10; Fig. 1C), full promoter activity of the ovine IFNT gene in response to ETS2 was restored (MatsudaMinehata et al. 2005). This experiment indicated the importance of the neighboring sequences to the core ETS2-binding site. Finally, ETS2 was significantly more efficient than related ETS family transcription factors, such as ELF1, ETS1, FLI1, ETV4 and SPI1 and was concurrently expressed with IFNT in trophectoderm of day 15 ovine conceptuses (Ezashi et al. 1998).

ETS2 is a master regulator of trophoblast differentiation across species. In the mouse, Ets2 is essential for trophoblast development (Yamamoto et al. 1998, Georgiades \& Rossant 2006) and trophoblast stem (TS) cell self-renewal (Wen et al. 2007, Odiatis \& Georgiades 2010). The ETS2 transcription factor controls many trophoblast signature genes including $\mathrm{Cd} 2$ (Wen et al. 2007) and Hand 1 (Odiatis \& Georgiades 2010) in mice, CGA (Ghosh et al. 2005) and CGB5 (Johnson \& Jameson 2000, Ghosh et al. 2003) in humans and pregnancyassociated glycoprotein 2 (PAG2) (Szafranska et al. 2001) and trophoblast Kunitz domain protein-1 (TKDP1) (Chakrabarty \& Roberts 2007) in ruminants. Secretion of PAG2 and TKDP1 begins concurrently with IFNT in ruminant trophectoderm (Green et al. 1998, MacLean et al. 2003).

The success obtained with yeast one-hybrid screening to identify ETS2 as a factor that associated with the proximal region of the IFNT 5'UTR was not so fruitful when applied to search the distal region ( -358 to $-322 \mathrm{bp})$ for binding factors. Various gene products with generally weak interactions were initially identified, but after several rounds of the onehybrid screening with different background threshold level, no consistent and plausible candidates for binding factors were found (T Ezashi and R M Roberts unpublished observation).

Although bovine and ovine IFNT genes have relatively conserved 5'UTR to around $-400 \mathrm{bp}$, their nucleotide sequences diverge considerably beyond that point (Ealy et al. 2001), suggesting that if control elements do exist they may be gene specific. In the ovine IFNT gene (ovIFNT-o10), a JUN/FOS (AP1) site was identified within the -654 to $-555 \mathrm{bp}$ region and appeared to have a regulatory function (Yamaguchi et al. 1999). It formed a DNA-protein complex with nuclear extracts of JEG3 choriocarcinoma cells and mediated responses to phorbol 12-myristate 13-acetate (PMA) treatment by an ovine IFNT-SV40 hybrid reporter (Yamaguchi et al. 2001). This site appears to be involved with a coactivator, cAMP-response element-binding protein-binding protein (CREBBP) (Xu et al. 2003). However, different responses to the AP1 site mutations at -602 to -592 in the two bovine IFNT genes, IFNT1 and IFNT-C1 that appears to be homologous to the AP1 site in the ovine IFNT gene, were observed. In the latter gene, the AP1 mutation did not change the transcriptional activity (Sakurai et al. 2013b).

Closely juxtaposed ETS- and AP1-binding motifs in plasminogen activator urokinase (PLAU), and chorionic somatomammotropin hormone $(\mathrm{CSH} 2)$ genes serve as a target of the RAS-mediated mitogen-activated protein kinase (MAPK) signaling pathway (Stacey et al. 1995, Sun \& Duckworth 1999) (Fig. 1A and B). Signaling through this pathway leads to phosphorylation of a highly conserved threonine residue in ETS2 at threonine 72 (T72) and stimulates ETS2-driven transcriptional responses (Yang et al. 1996). The proximal regions of IFNT genes possess a similar consensus AP1 site at -71 adjacent to the ETS site (Figs 1A, C, 2B and 3), which is also responsive to RAS-mediated signaling (Ezashi \& Roberts 2004). In all respects, the ETS/AP1-binding motif in the IFNT behaved identically to the one in the murine PLAU gene (Fig. 1B). Mutating T72 to alanine (A72) of ETS2 and mutation of the AP1 site in the ETS/AP1-binding motif ( $\mu \mathrm{AP} 1$, Fig. $2 \mathrm{~B}$ ) reversed the RAS effect on the IFNT

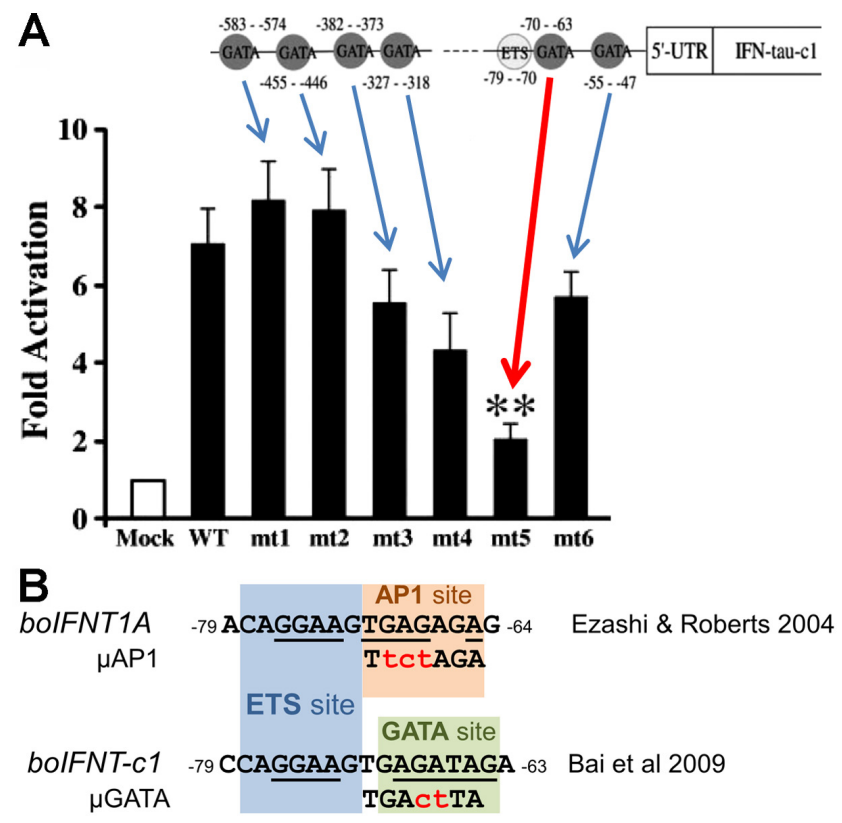

Figure 2 (A) ETS2 and potential six GATA-binding sites in the regulatory region of the bovine IFNT gene. Below is the transcriptional activity of the GATA site mutated IFNT reporters (mt1-mt6) with GATA2 expression plasmid. 'Mock' and 'WT' are readings of the wild-type $-631 \mathrm{bp}$ IFNT reporter construct without and with GATA2 expression plasmid, respectively. The reporter activities and the location of the six mutation sites are shown with arrows. Significant reduction $(P<0.01)$ of the transcriptional activity is noted with a red arrow and two asterisks on the mutation site, -70 to $-63(\mathrm{mt} 5)$. The image has been modified from Bai et al. (2009).

(B) The bovine IFNT upstream region adjacent to the ETS-binding site ( -79 to -70 , blue) is shown as AP1 site ( -71 to -65 , orange) in Ezashi and Roberts (2004) or GATA site ( -70 to -63 , green, $\mathrm{mt} 5$ site in $\mathrm{A}$ ) in Bai et al. (2009). Conserved core binding sequences are underlined. Introduced mutation sequences are shown in red. 
promoter. This study also demonstrated the importance of the AP1 site adjacent to ETS2 at -71 relative to other potential AP1-binding sites in the $-1675 \mathrm{bp}$ region of 5'UTR control region, none of which were responsive to RAS-mediated signaling (Ezashi \& Roberts 2004).

\section{$D L X 3$}

Having shown that ETS2 was a major player in controlling IFNT expression, it was natural to examine other important transcription factors that had been implicated in trophoblast differentiation in the human and mouse. $D L X 3$ is a member of the distal-less family of nonAntennapedia homeobox genes. Its knock out in mouse embryos leads to embryonic death due to placental failure by about day 10 of pregnancy (Morasso et al. 1999). DLX3 is also expressed in human, cow and mouse trophoblast cells (Panganiban \& Rubenstein 2002, Ezashi et al. 2008). It is upregulated during formation of human syncytiotrophoblast (Yabe et al. 2016) and has a role in the control of human CGA (Roberson et al. 2001), placental growth factor (PGF) (Li \& Roberson 2017a) and murine $3 \beta$-hydroxysteroid dehydrogenase $\mathrm{VI}$ (Hsd3b6) expressions (Peng \& Payne 2002, Berghorn et al. 2005). The DLX3-binding site (-54 GATAATGAG -46), which lies between the ETS2-binding site and the transcription start site of IFNT 5'UTR, is conserved in all IFNT genes examined (Fig. 3). Overexpression of DLX3 in JAr cells transactivated the bovine IFNT1A 10 to 20 -fold, whereas mutations introduced into the DLX3-binding site at -54 to -46 abolished the activation effect (Ezashi et al. 2008). In combination with ETS2 overexpression, DLX3 increased the IFNT reporter activity more than 250fold (Fig. 4). However, if the ETS2-binding site $(-79$ to -70$)$ was mutated ( $\mu \mathrm{ETS} 2)$ or deleted, the effects of DLX3 on reporter gene transactivation were abolished, suggesting that a major portion of DLX3 transactivation activity was dependent on the presence of ETS2 at a site just two helical turns ( 20 bp) upstream of the DLX3 site (Fig. 3). Suppression of bovine DLX3 expression by siRNA led to reductions of both intracellular IFNT protein and antiviral activity released into the medium of bovine trophectoderm CT-1 cell culture. Moreover, the two transcription factors (ETS2 and DLX3) were co-immunoprecipitated together as a complex in the IFNT-expressing CT-1 cell line. Clearly, DLX3 partners ETS2 in a cooperative and dependent manner to regulate IFNT expression in trophectoderm (Ezashi et al. 2008). DLX3 also interacts with another transcription factor, GCM1, to regulate PGF expression in human trophoblasts (Li \& Roberson 2017a,b).

\section{GATA2 and GATA3}

In the mouse placenta, D/x3 expression is controlled by GATA2 and -3 transcription factors (Home et al. 2017). These transcription factors are also regulators of mouse trophoblast differentiation (Home et al. 2009, Ray et al. 2009, Ralston et al. 2010). They are expressed in the bovine CT-1 cell line and in day 15-21 bovine and ovine conceptuses (Bai et al. 2009, 2014). GATA2 but not GATA3 overexpression also appeared capable of increasing expression from an IFNT reporter in nontrophoblast cells, namely bovine ear-derived fibroblasts (Bai et al. 2009). Similar experiments in JEG3 cells failed to reproduce the effect, possibly because JEG3 cells already express endogenous GATA2 or -3 in abundant quantities. This inference may be correct as siRNA silencing of GATA2 did decrease IFNT-C1-reporter expression (Bai et al. 2009). A search of six possible GATA sites as possible control elements for IFNT transcription identified only one ( -70 to -63 ; Fig. $2 \mathrm{~A}$,

\begin{abstract}
$\begin{array}{lllll}-79 & -70 & -60 & -50 & -46\end{array}$
bolFNT1A ACAGGAAGTGAGAGAGAAATTTTCGGATAATGAG

bolFNT ACAGGAAGTGAGAGAGAATTTTCGGATAATGAG

bolFNT1C ACAGGAAGTGAGAGAGAAATTTCGGATAATGAG

bolFNT2B ACAGGAAGTGAGAGAGAAATTTTCGGATAATGAG

bolFNT3B ACAGGAAGTGAGAGAGAAATTTTCGGATAATGAG

bolFNT-c1 CCAGGAAGTGAGATAGAAATTTTGGATAATGAA

ovIFNT-p7 ACAGGAAGTGAGGGAGGAATTTTTGGATAATGAG

ovIFNT-010 ACAGGAAGTGAGGGAGGAATGTTTGGATAATGAG

Goat IFNT ACAGGAAGTGAGGGAGGAATTTTCGGATGATGAG

Giraffe IFNT ACAGGAAGTGAGAGAGAAATTTTGGGATAATGAG ETS2 AP1/

bolFNW TACAAGTACACAGAAATGACTAGAAAATGAAAAC

ovIFNW TAAAAGTGCATAGAAATGACTAGAAAATGAAAAC
\end{abstract}

Hansen et al 1991

Stewart et al 1990

Ealy et al 2001

Ealy et al 2001

Ealy et al 2001

Chung \& Seidel 2000

Leaman \& Roberts 1992

Nephew et al 1993

Leaman \& Roberts 1992

Liu et al 1996

Leaman \& Roberts 1992

Leaman \& Roberts 1992
Figure 3 Sequence alignment of upstream regulatory regions ( -79 to -46 ) of IFNT and IFNW genes from various species, including bovine (bo) and ovine (ov). The IFNT sequences contained a conserved ETS2binding site (blue), putative AP1-binding site (orange) or GATA-binding site (green) and DLX3-binding site (yellow). The corresponding regions of IFNW genes do not contain such sequence motifs. The references for the sequences are bolFNT1A (Hansen et al. 1991); bolFNT (Stewart et al. 1990); bolFNT1C, $-2 B$ and $-3 B$ (Ealy et al. 2001); ovIFNT-p7, goat IFNT, boIFNW and ovIFNW (Leaman \& Roberts 1992); ovIFNT-o10 (Nephew et al. 1993); and giraffe IFNT (Liu et al. 1996). The bolFNT-c1 sequence is direct submission to GenBank (AF238613) by Chung and Seidel in 2000. A thymine (T) at -66 (bold letter) is unique to the bolFNT-c1 gene that makes a putative GATA binding site but the base is not conserved in other IFNT genes. 


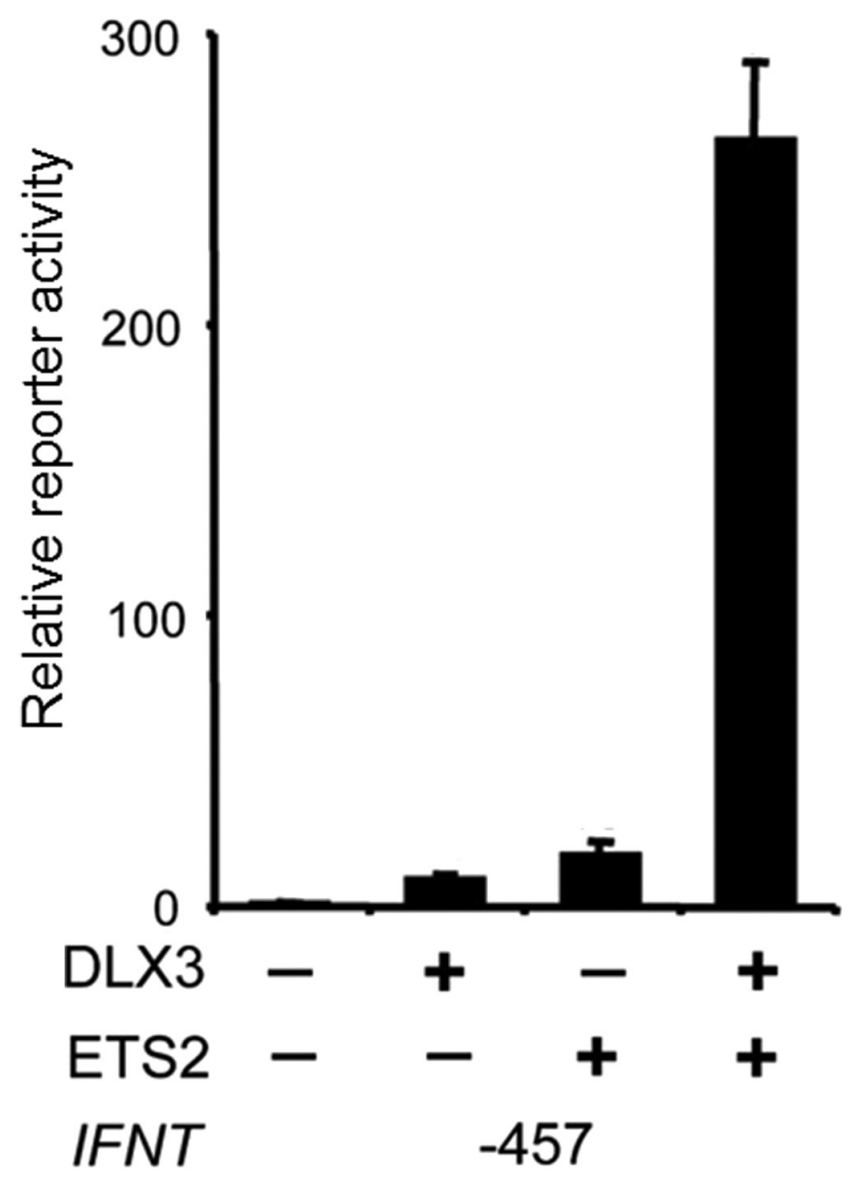

Figure 4 Cooperation of ETS2 and DLX3 in the transactivation of IFNT. The -457 bolFNT1A construct was transfected into choriocarcinoma JAr cells in either the absence (-) or presence (+) of the DLX3 or ETS2 expression plasmids. Values on $Y$ axis represent fold activations with the basal activity of the -457 reporter set as 1 . Obtained from Ezashi et al. (2008).

red arrow) that, when mutated, reduced IFNT expression to that of mock-transfected cells. Interestingly, the -70 to -63 site overlaps the previously reported AP1 site $(-71$ to -64$)$ adjacent to the ETS2-binding site at -79 to -70 (Ezashi \& Roberts 2004) (Fig. 2B). However, the generality of these data implicating GATA2 and GATA3 in control of IFNT expression should be treated with caution. First, the positive effects of GATA2 were only noted in a non-trophoblast cell line. Second, of all the ovine and bovine genes studied, only bovine IFNT-C1 has the unique thymine (T) at -66 instead of the common guanine $(\mathrm{G})$ present in other IFNT genes (Fig. 3). Finally, an introduced GATA site mutation also disturbs the AP1-binding site sequence (Fig. 2B). Clearly, further studies are needed to address whether GATA factors directly interact with the IFNT regulatory regions or even modulate IFNT promoter activity in trophoblast. Another possibility is that they act indirectly through other GATA2 and -3 regulated genes, such as DLX3 (Home et al. 2017).
CDX2

Caudal-type homeobox transcription factor CDX2, like ETS2, AP1, DLX3 and GATA2 and -3, plays an essential role in trophoblast lineage emergence and maintenance in the mouse and possibly other species (Strumpf et al. 2005, Ralston \& Rossant 2008, Roberts \& Fisher 2011). When the relative expression of IFNT
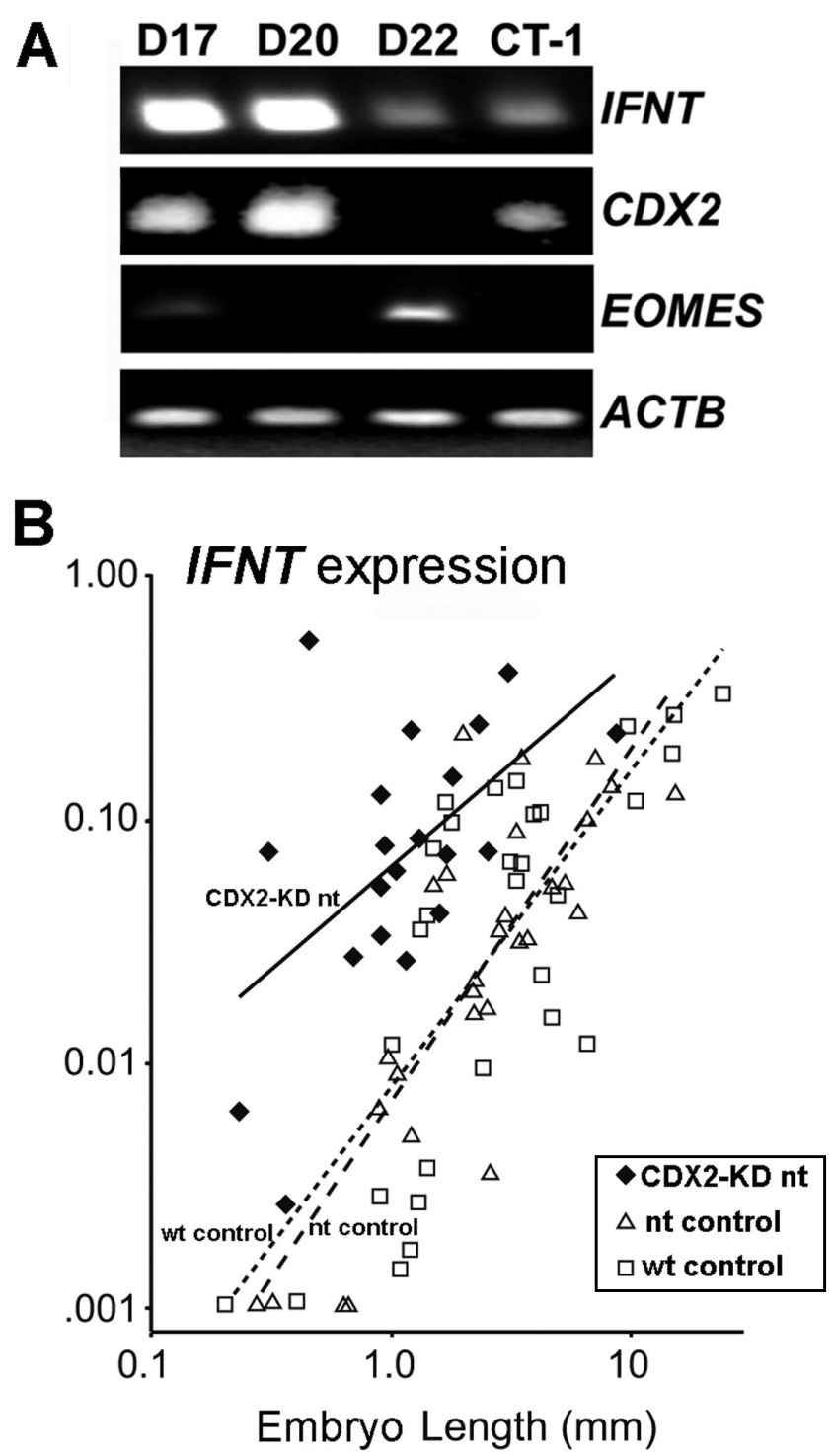

Figure 5 (A) RT-PCR analysis of IFNT, CDX2 and EOMES expressions in bovine conceptus at days 17, 20 and 22 by Sakurai et al. (2013a). Amplicons from ACTB served as loading controls. (B) CDX2-

knockdown (KD) bovine embryos were compared by IFNT expression ( $Y$ axis) and embryo size ( $X$ axis) to matched nuclear transfer ( $n t)$ and wild-type (wt) embryos by Berg et al. (2011). CDX2 expression was decreased by $72 \%$ in the KD embryos. Regression lines are solid for CDX2-KD nt, dashed for nt control and dotted for wt control embryos. Wt and nt generated control embryos expressed IFNT in proportion to their embryo size in length. Smaller sized CDX2-KD nt embryos expressed IFNT in amounts comparable to much larger WT embryos. 
and CDX2 transcripts were compared in ovine (days 14-20) and bovine (days 17-22) conceptuses during the peri-implantation period, roughly similar expression patterns over time were observed (Sakurai et al. 2010, 2013a) (Fig. 5A), suggesting a possible link between the two. Perhaps of note, ovine CDX2 expression became undetectable around day 20 at a time coincident with trophectoderm attachment to the uterine epithelium and ovine IFNT silencing (Helmer et al. 1987, Ealy et al. 2001). Some co-transfection experiments performed on human choriocarcinoma JEG3 cells have also suggested a possible role for CDX2 in the transactivation of IFNT genes (Imakawa et al. 2006). There is also an indication that CDX2 in combination with a number of other transcription factors, including ETS2 and AP1 might also be capable of upregulating endogenous IFNT gene transcription in non-trophoblast bovine ear-derived fibroblast cells, which do not normally express either IFNT or CDX2 (Fig. 6A) (Sakurai et al. 2009, 2013b). Possibly CDX2 expression contributes to a partial transdifferentiation of the mesodermal fibroblast cells to trophoblast-like and a permissive environment for low levels of IFNT transcription.
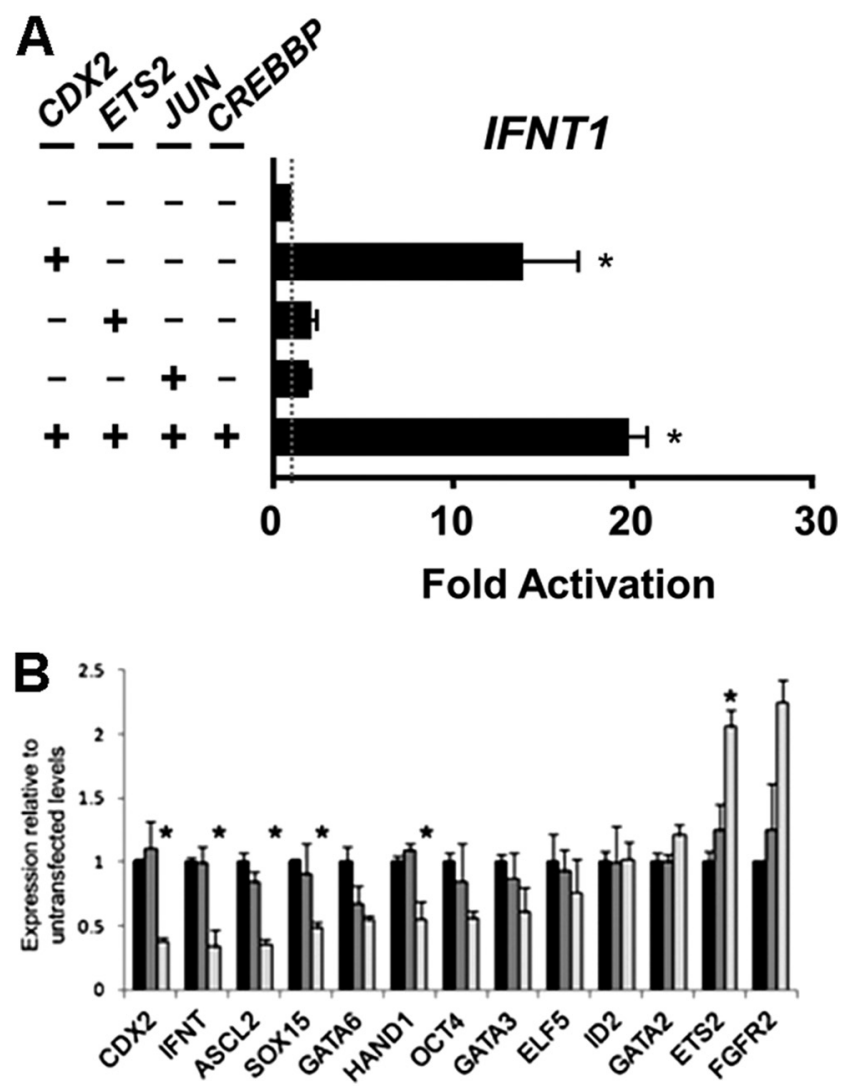

Figure 6 (A) Bovine IFNT1-reporter activity with CDX2, ETS2, JUN (AP1) and CREBBP expression plasmids. The plasmids were transfected in bovine ear-derived fibroblasts. Copied from Sakurai et al. (2013b). (B) 62\% CDX2 reduction by siRNA in CT-1 cells reduces expressions of some genes including IFNT but increases ETS2. Copied from Schiffmacher and Keefer (2013).
Some confusion exists as to the location of the site of CDX2 interaction with the 5'UTR of IFNT. One, apparently functional site, was reported between -581 and $-575 \mathrm{bp}$ in an ovine IFNT gene (Imakawa et al. 2006). Later, potential CDX2-binding sites were noted in a more proximal site at -248 to $-47 \mathrm{bp}$ of bolFNT-C 1 (Sakurai et al. 2009) and between -414 and $-235 \mathrm{bp}$ in an ovine IFNT (Sakurai et al. 2010). CDX2 knockdown in bovine trophectoderm BT-1 (Sakurai et al. 2009) and CT-1 cells (Schiffmacher \& Keefer 2013) (Fig. 5B) has also implicated a role for CDX2 in controlling IFNT expression.

However, other investigators have presented contrasting interpretation on the effects of CDX2 knockdown. For example, no effect was noted in with day 7.5 bovine blastocysts (Goissis \& Cibelli 2014). Essentially negative results were also reported with day 14 conceptuses (Berg et al. 2011). For example, when CDX2-knockdown conceptuses were transferred to the uteri of synchronized recipient cows and recovered a week later, they were significantly shorter in the size than controls. However, these treated conceptuses expressed IFNT at levels equivalent to that of the control conceptuses (Fig. 5B). From these results, it would appear that CDX2 is required for trophoblast development but not for IFNT expression. Clearly, further studies are required if this conundrum is to be solved.

\section{Multiplicity of IFNT genes}

Multiple IFNT genes exist in most ruminant species studied (Leaman \& Roberts 1992). Those expressed in cattle have been categorized into three groups (Ealy et al. 2001, Walker et al. 2009), and it is clear that not all these genes are expressed equivalently in the same conceptus (Walker et al. 2009) and that relative expression of each can change over development (Walker et al. 2009, Sakurai et al. 2013b). Yet, most known IFNT genes have highly conserved sequences within the ETS2AP1-DLX3 enhancer region ( -79 to -46$)$ (Fig. 3). The sequences in Fig. 3 do not include those of ovine IFNT that are poorly expressed and contain a mutation in the ETS-binding site (Ezashi et al. 1998, Leaman \& Roberts 1992, Nephew et al. 1993). All genes in the list contain the ETS2, the putative AP1 and the DLX3-binding sites. However, the presence of a GATA-binding site is limited to the bovine IFNT-C1. Note also the lack of conservation in the corresponding region of IFNW. Little is known about the function of the latter, although more than 20 apparently functional IFNW are found in the bovine genome (Walker \& Roberts 2009).

\section{Mechanisms that upregulate IFNT gene transcription following blastocyst formation}

IFNT is not secreted by morula stage conceptuses and is only modestly produced at the day 8 blastocyst 
stage, but levels of its mRNA and total IFN production increase markedly as the conceptus begins to expand and then elongate (Farin et al. 1990, Kubisch et al. 1998, Ealy et al. 2001). ETS2, the master regulator of IFNT transcription, is expressed in trophoblasts of E5.0 stage mouse embryos and is a necessary factor for placental development (Yamamoto et al. 1998, Georgiades \& Rossant 2006), TS cell (Wen et al. 2007, Kubaczka et al. 2015) and transcription of key placental hormones (Ghosh et al. 2003, 2005, Das et al. 2008). The initial low IFNT expression per cell in blastocyst stage ovine and bovine conceptuses has been speculated to be due to suppression by persistence of the POU domain class 5 transcription factor 1 (POU5F1 often known as OCT4) (Ezashi et al. 2001) that is expressed in early ruminant and primate trophectoderm (Van Eijk et al. 1999, Niakan \& Eggan 2013) (Fig. 7). Both CGA and CGB were efficiently silenced by overexpressing POU5F1 in choriocarcinoma cells (Liu \& Roberts 1996, Liu et al. 1997). We initially proposed that POU5F1 silenced IFNT by quenching, i.e., the silencer (=POU5F1 in this case) interferes with the ability of the DNAbound transactivator (=ETS2) to interact with the basal transcriptional machinery (Ezashi et al. 2001). However, a more recent study of CGA silencing (Gupta et al. 2012) demonstrated a squelching mechanism, i.e., POU5F1 sequesters free ETS2 and prevents ETS2 from binding to the DNA. It can be speculated that this mechanism also operates for IFNT (Fig. 7). As trophoblast differentiation proceeds, POU5F1 becomes reduced in amount, and other trophoblastic gene regulators such as DLX3, CDX2 and GATA2/3 become upregulated. However, there are some conflicting observations that counter this hypothesis. When, for example, POU5F1 was overexpressed in CT-1 cells, IFNT expression appeared not to be suppressed (Schiffmacher \& Keefer 2013). In that experiment, overexpressed POU5F1 only changed ASCL2 expression among the cohort of genes examined.
Because so few changes in trophoblast gene expression were observed when $>60 \%$ of POU5F1 transcripts had been knocked down, it remains unclear whether the expressed POU5F1 levels play a role in the gene regulatory network of CT-1 cells.

\section{Regulatory mechanisms that downregulate IFNT gene transcription}

Following the dramatic, short-term increase in IFNT transcription during the elongation phase of development, the expression of these genes is rapidly downregulated when the trophectoderm attaches to the uterine epithelium (Helmer et al. 1987, Ealy et al. 2001). Precisely what mediates these events is unclear. However, downregulation of in vivo IFNT gene could be mimicked in CT-1 cells when the cells were cultured with bovine uterine epithelium cells (Sakurai et al. 2013a). The transcription factor T-box protein eomesodermin (EOMES) has been implicated in this silencing phenomenon, in part because its expression increases in trophectoderm following the conceptus attachment (Fig. 5A) (Sakurai et al. 2013a). One explanation is that EOMES associates with the coactivator CREBBP and reduces its binding to AP1 (Xu et al. 2003), thereby disrupting transactivation of IFNT by ETS2/AP1 (Sakurai et al. 2013a) (Fig. 7). There are also suggestions that the relocation of TEAD2/4 from the nucleus to the cytoplasm leads to the downregulation of IFNT expression (Kusama et al. 2016), but this observation needs to be confirmed in future studies.

\section{Epigenetic regulation}

There is some limited evidence that epigenetic as well as genetic mechanisms might regulate IFNT expression. For example, endogenous IFNT expression was increased in bovine skin fibroblasts when CDX2 was overexpressed
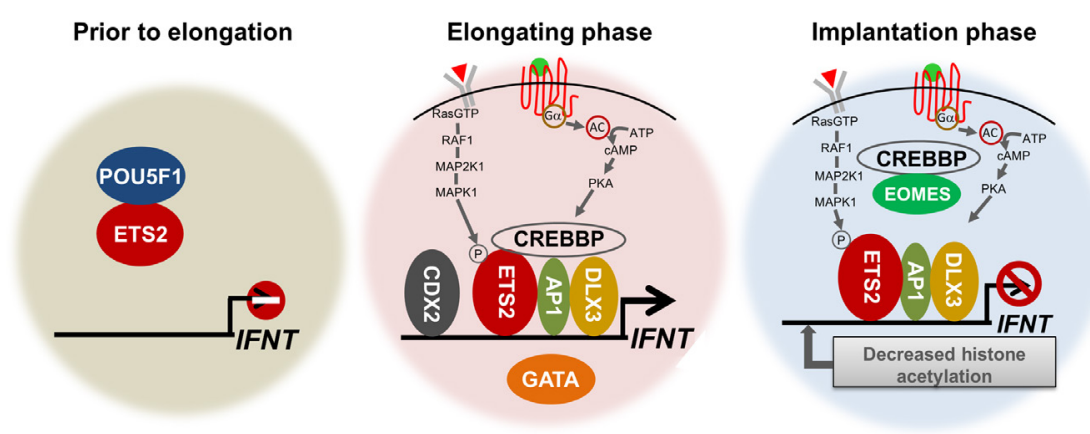

www.reproduction-online.org
Figure 7 Summary of speculative models for IFNT transcriptional control at prior to conceptus elongation (left), elongation phase (middle) and implantation (right). Before conceptus elongation, presence of POU5F1 in the early stage trophectoderm suppresses IFNT expression through squelching ETS2. When the conceptus elongates, trophoblastic gene regulators DLX3, CDX2, and GATA2/3 become upregulated. Growth factors released from maternal endometrium activate MEK/ERK and PKA signaling pathways and increase IFNT expression through the transcription factors. When the trophectoderm firmly attaches to the uterine epithelium in the implantation stage, the IFNT expression is down-regulated. The silencing is accompanied by EOMES association with CREBBP coactivator and reduction of histone acetylation of the IFNT gene upstream region. 
and the cultures were treated with a histone deacetylase inhibitor (Sakurai et al. 2010). Further evidence came from chromatin immunoprecipitation (ChIP) assays performed on elongating ovine conceptuses (days $14,16,16.5$ and 20) to determine the acetylation status of histone $\mathrm{H} 3$ at the lysine-18 residue (H3K18) (Sakurai et al. 2010). Elevated H3K18 acetylation of the ovine IFNT gene was observed on days 14 and 16 but declined when the conceptus had initiated attachment to the uterine wall (Fig. 7). The authors also inferred H3K18 association with the -414 to $-235 \mathrm{bp}$ of the $5^{\prime}$ UTR and the CDX2-binding sites ( -300 to $-294 \mathrm{bp}$ and -293 to $-287 \mathrm{bp}$ ) within the ovine gene (Sakurai et al. 2010). In addition, CDX2 overexpression in bovine ear-derived fibroblast cells increased histone acetylation and led to concurrent recruitment of CREBBP, a nuclear factor that has histone acetyltransferase activity. Acetylation of $\mathrm{H} 3 \mathrm{~K} 18$ was also detected in the proximity of the CDX2binding region of a bovine IFNT gene in IFNT-secreting CT-1 cells. Conversely, when CDX2 expression was inhibited by a small interfering RNA, H3K18 acetylation was decreased (Sakurai et al. 2010). These findings suggest that CDX2 regulates IFNT expression through CREBBP recruitment, which leads to greater H3K18 acetylation at CDX2-binding sites.

\section{Maternal factors and intracellular signaling that control IFNT expression}

Secretions from maternal endometrial glands including hormones and growth factors may play a promotive role for both induction of IFNT expression and conceptus growth (Gray et al. 2002, Satterfield et al. 2006, Roberts et al. 2008). For example, IFNT production from cultured blastocyst can be increased by supplementation of the medium with uterine flushing (Kubisch et al. 2001), which are known to contain colony-stimulating factor 2 (CSF2 also known as GM-CSF) (Imakawa et al. 1993), interleukin 3 (IL3) (Imakawa et al. 1995) and fibroblast growth factor-2 (FGF2) (Michael et al. 2006, Ocon-Grove et al. 2008, Rodina et al. 2009). Each of these cytokines can individually increase transcription from IFNT, presumably through cell signaling pathways initiated by the cognitive receptor complexes. For example, CSF1, which is also present in uterine secretions, and its cognate receptor CSF1R (c-fms), expressed in the bovine trophoblast, can both exert MEK/ERK pathway transduction and increase IFNT expression (Ezashi \& Roberts 2004) (Fig. 7). Additionally, overexpression of the catalytic subunit of protein kinase A (PKA) in combination with ETS2 overexpression induced a 500-fold upregulation of IFNT (Das et al. 2008). Presumably, growth factors released from maternal endometrium in combination with PKA, MEK/ERK and PKC signaling pathways and a combination of necessary transcription factors can provide the massive upregulation of IFNT observed in the elongating conceptus (Fig. 7).

\section{Conclusion}

The IFNT genes diverged from those encoding its closest type I IFN family, IFNW, about 36 million years ago when the ruminant species started to emerge within the artiodactyl order (Roberts et al. 1997) and was probably initiated when a progenitor IFNW gene exchanged in some manner its viral response elements for ones that favored trophoblast expression. The acquired transcriptional control elements drive IFNT expression in trophoblast, which is then sustained over several days without viral infection (Roberts et al. 2008). The studies on IFNT gene regulation first focused on what regions of the gene were responsible for trophoblast expression and what transcription factors were involved. Later studies emphasized the role of external factors and signaling pathways and why the high-level expression became silenced after only a few days. More recently, emphasis has switched to epigenetic regulation. In particular, it was noted that many of the transcription factors that regulate trophoblast emergence and development elucidated in mouse studies play a role in trophoblast-specific IFNT gene expression. The studies confirm that there is a core group of transcription factors that probably operate across all mammals to initiate trophoblast emergence. However, these same factors may also guide unique aspects of the trophoblast phenotype, such as production of hormones and other signature events that are peculiar to a particular taxonomic group. Representative findings of IFNT gene control are summarized in three stages of conceptus development (Fig. 7). Modest IFNT expression in early trophectoderm prior to conceptus elongation can be explained by a presence of POU5F1, which suppresses ETS2 transactivation. Species-specific onset patterns of trophoblastic gene expression, including IFNT, might be linked to a time length of persisted POU5F1 protein in trophoblasts that is very limited in rodents. Large increases of IFNT expression in the elongation phase appears to be combinatory by upregulated trophoblastic gene regulators (DLX3, CDX2, GATA2/3) and growth factors released from maternal endometrium that activate MEK/ERK and PKA signaling pathways in trophoblasts. The downregulation mechanism of IFNT expression at implantation phase has been anticipated by decreased histone acetylation of the regulatory region of IFNT gene and the association of EOMES and CREBBP that lead to disruption of a transactivation complex of IFNT gene.

\section{Declaration of interest}

The authors declare that there is no conflict of interest that could be perceived as prejudicing the impartiality of this review. 


\section{Funding}

This work was supported by National Institute of Health HD21896, HD42201 to R M Roberts, HD77108 to T E, Grants-in-Aid for Scientific Research (14206032, 18108004, $16 \mathrm{H} 02584$ ) from the Japan Society for the Promotion of Science, the Program for Promotion of Basic Research Activities for Innovative Bioscience (BRAIN, H20) and the Science and Technology Research Promotion Program (25030AB) for Agriculture, Forestry, and Fisheries (MAFF), Japan to K I.

\section{References}

Bai H, Sakurai T, Kim MS, Muroi Y, Ideta A, Aoyagi Y, Nakajima H, Takahashi M, Nagaoka K \& Imakawa K 2009 Involvement of GATA transcription factors in the regulation of endogenous bovine interferontau gene transcription. Molecular Reproduction and Development $\mathbf{7 6}$ 1143-1152. (doi:10.1002/mrd.21082)

Bai H, Sakurai T, Bai R, Godkin JD \& Imakawa K 2014 Localization of GATA2 in the nuclear and cytoplasmic regions of ovine conceptuses. Animal Science Journal 85 981-985. (doi:10.1111/asj.12267)

Berg DK, Smith CS, Pearton DJ, Wells DN, Broadhurst R, Donnison M \& Pfeffer PL 2011 Trophectoderm lineage determination in cattle. Developmental Cell 20 244-255. (doi:10.1016/j.devcel.2011.01.003)

Berghorn KA, Clark PA, Encarnacion B, DeRegis CJ, Folger JK, Morasso MI, Soares MJ, Wolfe MW \& Roberson MS 2005 Developmental expression of the homeobox protein Distal-less 3 and its relationship to progesterone production in mouse placenta. Journal of Endocrinology 186 315-323. (doi:10.1677/joe.1.06217)

Chakrabarty A \& Roberts MR 2007 Ets-2 and C/EBP-beta are important mediators of ovine trophoblast Kunitz domain protein-1 gene expression in trophoblast. BMC Molecular Biology 8 14. (doi:10.1186/14712199-8-14)

Cross JC \& Roberts RM 1991 Constitutive and trophoblast-specific expression of a class of bovine interferon genes. PNAS 88 3817-3821. (doi:10.1073/pnas.88.9.3817)

Das P, Ezashi T, Gupta R \& Roberts RM 2008 Combinatorial roles of protein kinase A, Ets2, and 3',5'-cyclic-adenosine monophosphate response element-binding protein-binding protein/p300 in the transcriptional control of interferon-tau expression in a trophoblast cell line. Molecular Endocrinology 22 331-343. (doi:10.1210/me.2007-0300)

Ealy AD \& Yang QE 2009 Control of interferon-tau expression during early pregnancy in ruminants. American Journal of Reproductive Immunology 61 95-106. (doi:10.1111/j.1600-0897.2008.00673.x)

Ealy AD, Larson SF, Liu L, Alexenko AP, Winkelman GL, Kubisch HM, Bixby JA \& Roberts RM 2001 Polymorphic forms of expressed bovine interferon-tau genes: relative transcript abundance during early placental development, promoter sequences of genes and biological activity of protein products. Endocrinology 142 2906-2915. (doi:10.1210/ endo.142.7.8249)

Ealy AD \& Woolridge D 2017 The Evolution of IFNT. Reproduction 154 F1-F10. (doi:10.1530/REP-17-0292)

Ezashi T, Ealy AD, Ostrowski MC \& Roberts RM 1998 Control of interferontau gene expression by Ets-2. PNAS 95 7882-7887. (doi:10.1073/ pnas.95.14.7882)

Ezashi T, Ghosh D \& Roberts RM 2001 Repression of Ets-2-induced transactivation of the tau interferon promoter by Oct-4. Molecular and Cellular Biology 21 7883-7891. (doi:10.1128/MCB.21.23.78837891.2001)

Ezashi T \& Roberts RM 2004 Regulation of interferon-tau (IFN-tau) gene promoters by growth factors that target the Ets-2 composite enhancer: a possible model for maternal control of IFN-tau production by the conceptus during early pregnancy. Endocrinology 145 4452-4460. (doi:10.1210/en.2004-0606)

Ezashi T, Das P, Gupta R, Walker A \& Roberts RM 2008 The role of homeobox protein distal-less 3 and its interaction with ETS2 in regulating bovine interferon-tau gene expression-synergistic transcriptional activation with ETS2. Biology of Reproduction 79 115-124. (doi:10.1095/ biolreprod.107.066647)
Farin CE, Imakawa K, Hansen TR, McDonnell JJ, Murphy CN, Farin PW \& Roberts RM 1990 Expression of trophoblastic interferon genes in sheep and cattle. Biology of Reproduction 43 210-218. (doi:10.1095/ biolreprod43.2.210)

Flint AP, Guesdon FM \& Stewart HJ 1994 Regulation of trophoblast interferon gene expression. Molecular and Cellular Endocrinology 100 93-95. (doi:10.1016/0303-7207(94)90285-2)

Georgiades P \& Rossant J 2006 Ets2 is necessary in trophoblast for normal embryonic anteroposterior axis development. Development 133 1059-1068. (doi:10.1242/dev.02277)

Ghosh D, Ezashi T, Ostrowski MC \& Roberts RM 2003 A central role for Ets-2 in the transcriptional regulation and cyclic adenosine $5^{\prime}$-monophosphate responsiveness of the human chorionic gonadotropin-\{beta\} subunit gene. Molecular Endocrinology 17 11-26. (doi:10.1210/me.2002-0223)

Ghosh D, Sachdev S, Hannink M \& Roberts RM 2005 Coordinate regulation of basal and cyclic 5'-adenosine monophosphate (cAMP)-activated expression of human chorionic gonadotropin-alpha by Ets-2 and cAMPresponsive element binding protein. Molecular Endocrinology 19 1049-1066. (doi:10.1210/me.2004-0320)

Goissis MD \& Cibelli JB 2014 Functional characterization of CDX2 during bovine preimplantation development in vitro. Molecular Reproduction and Development 81 962-970. (doi:10.1002/mrd.22415)

Gray C, Burghardt R, Johnson G, Bazer F \& Spencer T 2002 Evidence that absence of endometrial gland secretions in uterine gland knockout ewes compromises conceptus survival and elongation. Reproduction 124 289-300. (doi:10.1530/rep.0.1240289)

Green JA, Xie S \& Roberts RM 1998 Pepsin-related molecules secreted by trophoblast. Review of Reproduction 3 62-69. (doi:10.1530/ ror.0.0030062)

Green MP, Spate LD, Bixby JA, Ealy AD \& Roberts RM 2005 A comparison of the anti-luteolytic activities of recombinant ovine interferon-alpha and -tau in sheep. Biology of Reproduction 73 1087-1093. (doi:10.1095/ biolreprod.105.043406)

Gupta R, Ezashi T \& Roberts RM 2012 Squelching of ETS2 transactivation by POU5F1 silences the human chorionic gonadotropin CGA subunit gene in human choriocarcinoma and embryonic stem cells. Molecular Endocrinology. 26 859-872. (10.1210/me.2011-1146)

Hansen TR, Leaman DW, Cross JC, Mathialagan N, Bixby JA \& Roberts RM 1991 The genes for the trophoblast interferons and the related interferonalpha II possess distinct 5'-promoter and 3'-flanking sequences. Journal of Biological Chemistry 266 3060-3067.

Helmer SD, Hansen PJ, Anthony RV, Thatcher WW, Bazer FW \& Roberts RM 1987 Identification of bovine trophoblast protein-1, a secretory protein immunologically related to ovine trophoblast protein-1. Journal of Reproduction and Fertility 79 83-91. (doi:10.1530/ jrf.0.0790083)

Home P, Ray S, Dutta D, Bronshteyn I, Larson M \& Paul S 2009 GATA3 is selectively expressed in the trophectoderm of peri-implantation embryo and directly regulates $\mathrm{Cdx} 2$ gene expression. Journal of Biological Chemistry 284 28729-28737. (doi:10.1074/jbc.M109.016840)

Home P, Kumar RP, Ganguly A, Saha B, Milano-Foster J, Bhattacharya B, Ray S, Gunewardena S, Paul A, Camper SA et al. 2017 Genetic redundancy of GATA factors in the extraembryonic trophoblast lineage ensures the progression of preimplantation and postimplantation mammalian development. Development 144 876-888. (doi:10.1242/ dev.145318)

Imakawa K, Helmer SD, Nephew KP, Meka CS \& Christenson RK 1993 A novel role for GM-CSF: enhancement of pregnancy specific interferon production, ovine trophoblast protein-1. Endocrinology 132 1869-1871. (doi:10.1210/endo.132.4.7681767)

Imakawa K, Tamura K, McGuire WJ, Khan S, Harbison LA, Stanga JP, Helmer SD \& Christenson RK 1995 Effect of interleukin-3 on ovine trophoblast interferon during early conceptus development. Endocrine 3 511-517. (doi:10.1007/BF02738826)

Imakawa K, Kim MS, Matsuda-Minehata F, Ishida S, lizuka M, Suzuki M, Chang KT, Echternkamp SE \& Christenson RK 2006 Regulation of the ovine interferon-tau gene by a blastocyst-specific transcription factor, Cdx2. Molecular Reproduction and Development 73 559-567. (doi:10.1002/mrd.20457)

Johnson W \& Jameson JL 2000 Role of Ets2 in cyclic AMP regulation of the human chorionic gonadotropin beta promoter. Molecular and Cellular Endocrinology 165 17-24. (doi:10.1016/S0303-7207(00)00269-0) 
Kubaczka C, Senner CE, Cierlitza M, Arauzo-Bravo MJ, Kuckenberg P, Peitz M, Hemberger M \& Schorle H 2015 Direct induction of trophoblast stem cells from murine fibroblasts. Cell Stem Cell 17 557-568. (doi:10.1016/j. stem.2015.08.005)

Kubisch HM, Larson MA \& Roberts RM 1998 Relationship between age of blastocyst formation and interferon-tau secretion by in vitroderived bovine embryos. Molecular Reproduction and Development 49 254-260. (doi:10.1002/(SICl)1098-2795(199803)49:3<254::AIDMRD5>3.0.CO;2-N)

Kubisch HM, Larson MA \& Kiesling DO 2001 Control of interferon-tau secretion by in vitro-derived bovine blastocysts during extended culture and outgrowth formation. Molecular Reproduction and Development 58 390-397. (doi:10.1002/1098-2795(20010401)58:4<390::AIDMRD6>3.0.CO;2-V)

Kusama K, Bai R, Sakurai T, Bai H, Ideta A, Aoyagi Y \& Imakawa K 2016 A transcriptional cofactor YAP regulates IFNT expression via transcription factor TEAD in bovine conceptuses. Domestic Animal Endocrinology $\mathbf{5 7}$ 21-30. (doi:10.1016/j.domaniend.2016.05.002)

Leaman DW \& Roberts RM 1992 Genes for the trophoblast interferons in sheep, goat, and musk ox and distribution of related genes among mammals. Journal of Interferon Research 12 1-11. (doi:10.1089/ jir.1992.12.1)

Leaman DW, Cross JC \& Roberts RM 1994 Multiple regulatory elements are required to direct trophoblast interferon gene expression in choriocarcinoma cells and trophectoderm. Molecular Endocrinology 8 456-468. (doi:10.1210/me.8.4.456)

Li S \& Roberson MS 2017a Dlx3 and GCM-1 functionally coordinate the regulation of placental growth factor in human trophoblast-derived cells. Journal of Cellular Physiology 232 2900-2914. (doi:10.1002/jcp.25752)

Li S \& Roberson MS 2017b DLX3 interacts with GCM1 and inhibits its transactivation-stimulating activity in a homeodomain-dependent manner in human trophoblast-derived cells. Scientific Reports 72009. (doi:10.1038/s41598-017-02120-5)

Liu L \& Roberts RM 1996 Silencing of the gene for the beta subunit of human chorionic gonadotropin by the embryonic transcription factor Oct-3/4. Journal of Biological Chemistry 271 16683-16689. (doi:10.1074/jbc.271.28.16683)

Liu L, Leaman DW \& Roberts RM 1996 The interferon-tau genes of the giraffe, a nonbovid species. Journal of Interferon and Cytokine Research 16 949-951. (doi:10.1089/jir.1996.16.949)

Liu L, Leaman D, Villalta M \& Roberts RM 1997 Silencing of the gene for the alpha-subunit of human chorionic gonadotropin by the embryonic transcription factor Oct-3/4. Molecular Endocrinology 11 1651-1658. (doi:10.1210/me.11.11.1651)

MacLean JA II, Chakrabarty A, Xie S, Bixby JA, Roberts RM \& Green JA 2003 Family of Kunitz proteins from trophoblast: expression of the trophoblast Kunitz domain proteins (TKDP) in cattle and sheep. Molecular Reproduction and Development 65 30-40. (doi:10.1002/ mrd.10262)

Matsuda-Minehata F, Katsumura M, Kijima S, Christenson RK \& Imakawa K 2005 Different levels of ovine interferon-tau gene expressions are regulated through the short promoter region including Ets-2 binding site. Molecular Reproduction and Development 72 7-15. (doi:10.1002/ mrd.20329)

Michael DD, Alvarez IM, Ocon OM, Powell AM, Talbot NC, Johnson SE \& Ealy AD 2006 Fibroblast growth factor-2 is expressed by the bovine uterus and stimulates interferon-tau production in bovine trophectoderm. Endocrinology 147 3571-3579. (doi:10.1210/en.2006-0234)

Morasso MI, Grinberg A, Robinson G, Sargent TD \& Mahon KA 1999 Placental failure in mice lacking the homeobox gene Dlx3. PNAS 96 162-167. (doi:10.1073/pnas.96.1.162)

Nephew KP, Whaley AE, Christenson RK \& Imakawa K 1993 Differential expression of distinct mRNAs for ovine trophoblast protein-1 and related sheep type I interferons. Biology of Reproduction 48 768-778. (doi:10.1095/biolreprod48.4.768)

Niakan KK \& Eggan K 2013 Analysis of human embryos from zygote to blastocyst reveals distinct gene expression patterns relative to the mouse. Developmental Biology 375 54-64. (doi:10.1016/j. ydbio.2012.12.008)

Ocon-Grove OM, Cooke FN, Alvarez IM, Johnson SE, Ott TL \& Ealy AD 2008 Ovine endometrial expression of fibroblast growth factor (FGF) 2 and conceptus expression of FGF receptors during early pregnancy.
Domestic Animal Endocrinology $34 \quad 135-145 . \quad$ (doi:10.1016/j. domaniend.2006.12.002)

Odiatis C \& Georgiades P 2010 New insights for Ets2 function in trophoblast using lentivirus-mediated gene knockdown in trophoblast stem cells. Placenta 31 630-640. (doi:10.1016/j.placenta.2010.05.001)

Panganiban G \& Rubenstein JLR 2002 Developmental functions of the Distal-less/Dlx homeobox genes. Development 129 4371-4386.

Peng L \& Payne AH 2002 AP-2gamma and the homeodomain protein distalless 3 are required for placental-specific expression of the murine 3betahydroxysteroid dehydrogenase VI gene, Hsd3b6. Journal of Biological Chemistry 277 7945-7954. (doi:10.1074/jbc.M106765200)

Ralston A, Cox BJ, Nishioka N, Sasaki H, Chea E, Rugg-Gunn P, Guo G, Robson P, Draper JS \& Rossant J 2010 Gata3 regulates trophoblast development downstream of Tead 4 and in parallel to Cdx2. Development 137 395-403. (doi:10.1242/dev.038828)

Ralston A \& Rossant J 2008 Cdx2 acts downstream of cell polarization to cell-autonomously promote trophectoderm fate in the early mouse embryo. Developmental Biology 313 614-629. (doi:10.1016/j. ydbio.2007.10.054)

Ray S, Dutta D, Rumi MA, Kent LN, Soares MJ \& Paul S 2009 Contextdependent function of regulatory elements and a switch in chromatin occupancy between GATA3 and GATA2 regulate Gata2 transcription during trophoblast differentiation. Journal of Biological Chemistry 284 4978-4988. (doi:10.1074/jbc.M807329200)

Roberson MS, Meermann S, Morasso MI, Mulvaney-Musa JM \& Zhang T 2001 A role for the homeobox protein Distal-less 3 in the activation of the glycoprotein hormone alpha subunit gene in choriocarcinoma cells. Journal of Biological Chemistry 276 10016-10024. (doi:10.1074/jbc. M007481200)

Roberts RM 2007 Interferon-tau, a Type 1 interferon involved in maternal recognition of pregnancy. Cytokine and Growth Factor Reviews 18 403-408. (doi:10.1016/j.cytogfr.2007.06.010)

Roberts RM, Cross JC \& Leaman DW 1992 Interferons as hormones of pregnancy. Endocrine Reviews 13 432-452. (doi:10.1210/er.13.3.432)

Roberts RM, ChenY, EzashiT \&WalkerAM 2008 Interferons and the maternalconceptus dialog in mammals. Seminars in Cell and Developmental Biology 19 170-177. (doi:10.1016/j.semcdb.2007.10.007)

Roberts RM \& Fisher SJ 2011 Trophoblast stem cells. Biology of Reproduction 84 412-421. (doi:10.1095/biolreprod.110.088724)

Roberts RM, Liu L \& Alexenko A 1997 New and atypical families of type I interferons in mammals: comparative functions, structures, and evolutionary relationships. Progress in Nucleic Acid Research and Molecular Biology 56 287-325. (doi:10.1016/s0079-6603(08)61008-9)

Rodina TM, Cooke FN, Hansen PJ \& Ealy AD 2009 Oxygen tension and medium type actions on blastocyst development and interferontau secretion in cattle. Animal Reproduction Science 111 173-188. (doi:10.1016/j.anireprosci.2008.02.014)

Sakurai T, Sakamoto A, Muroi Y, Bai H, Nagaoka K, Tamura K, Takahashi T, Hashizume K, Sakatani M, Takahashi M et al. 2009 Induction of endogenous interferon tau gene transcription by CDX2 and high acetylation in bovine nontrophoblast cells. Biology of Reproduction $\mathbf{8 0}$ 1223-1231. (doi:10.1095/biolreprod.108.073916)

Sakurai T, Bai H, Konno T, Ideta A, Aoyagi Y, Godkin JD \& Imakawa K 2010 Function of a transcription factor CDX2 beyond its trophectoderm lineage specification. Endocrinology 151 5873-5881. (doi:10.1210/ en.2010-0458)

Sakurai T, Bai H, Bai R, Sato D, Arai M, Okuda K, Ideta A, Aoyagi Y, Godkin JD \& Imakawa K 2013a Down-regulation of interferon tau gene transcription with a transcription factor, EOMES. Molecular Reproduction and Development 80 371-383. (doi:10.1002/mrd.22171)

Sakurai T, Nakagawa S, Kim MS, Bai H, Bai R, Li J, Min KS, Ideta A, Aoyagi Y \& Imakawa K 2013b Transcriptional regulation of two conceptus interferon tau genes expressed in Japanese black cattle during periimplantation period. PLOS ONE 8 e80427. (doi:10.1371/journal. pone.0080427)

Satterfield MC, Bazer FW \& Spencer TE 2006 Progesterone regulation of preimplantation conceptus growth and galectin 15 (LGALS15) in the ovine uterus. Biology of Reproduction 75 289-296. (doi:10.1095/ biolreprod.106.052944)

Schiffmacher AT \& Keefer CL 2013 CDX2 regulates multiple trophoblast genes in bovine trophectoderm CT-1 cells. Molecular Reproduction and Development 80 826-839. (doi:10.1002/mrd.22212) 
Stacey KJ, Fowles LF, Colman MS, Ostrowski MC \& Hume DA 1995 Regulation of urokinase-type plasminogen activator gene transcription by macrophage colony-stimulating factor. Molecular and Cellular Biology 15 3430-3441. (doi:10.1128/MCB.15.6.3430)

Stewart HJ, McCann SH \& Flint AP 1990 Structure of an interferon-alpha 2 gene expressed in the bovine conceptus early in gestation. Journal of Molecular Endocrinology 4 275-282.

Strumpf D, Mao CA, Yamanaka Y, Ralston A, Chawengsaksophak K, Beck F \& Rossant J 2005 Cdx2 is required for correct cell fate specification and differentiation of trophectoderm in the mouse blastocyst. Development 132 2093-2102. (doi:10.1242/dev.01801)

Sun Y \& Duckworth ML 1999 Identification of a placental-specific enhancer in the rat placental lactogen II gene that contains binding sites for members of the Ets and AP-1 (activator protein 1) families of transcription factors. Molecular Endocrinology 13 385-399. (doi:10.1210/mend.13.3.0243)

Szafranska B, Miura R, Ghosh D, Ezashi T, Xie S, Roberts RM \& Green JA 2001 Gene for porcine pregnancy-associated glycoprotein 2 (poPAG2): its structural organization and analysis of its promoter. Molecular Reproduction and Development 60 137-146. (doi:10.1002/mrd.1070)

Van Eijk MJ, Van Rooijen MA, Modina S, Scesi L, Folkers G, van Tol HT, Bevers MM, Fisher SR, Lewin HA, Rakacolli D et al. 1999 Molecular cloning, genetic mapping, and developmental expression of bovine POU5F1. Biology of Reproduction 60 1093-1103. (doi:10.1095/ biolreprod60.5.1093)

Walker AM \& Roberts RM 2009 Characterization of the bovine type I IFN locus: rearrangements, expansions, and novel subfamilies. BMC Genomics 10 187. (doi:10.1186/1471-2164-10-187)

Walker AM, Kimura K \& Roberts RM 2009 Expression of bovine interferontau variants according to sex and age of conceptuses. Theriogenology 72 44-53. (doi:10.1016/j.theriogenology.2009.01.017)

Wen F, Tynan JA, Cecena G, Williams R, Munera J, Mavrothalassitis G \& Oshima RG 2007 Ets2 is required for trophoblast stem cell selfrenewal. Developmental Biology 312 284-299. (doi:10.1016/j. ydbio.2007.09.024)
Xu N, Takahashi Y, Matsuda F, Sakai S, Christenson RK \& Imakawa K 2003 Coactivator CBP in the regulation of conceptus IFNtau gene transcription. Molecular Reproduction and Development 65 23-29. (doi:10.1002/mrd.10293)

Yabe S, Alexenko AP, Amita M, Yang Y, Schust DJ, Sadovsky Y, Ezashi T \& Roberts RM 2016 Comparison of syncytiotrophoblast generated from human embryonic stem cells and from term placentas. PNAS 113 E2598-E2607. (doi:10.1073/pnas.1601630113)

Yamaguchi H, Ikeda Y, Moreno J, Katsumura M, Miyazawa T, Takahashi E, Imakawa K \& Christenson RK 1999 Identification of a functional transcriptional factor AP-1 site in the sheep interferon tau gene that mediates a response to PMA in JEG3 cells. Biochemistry Journal 340 (Part 3) 767-773.

Yamaguchi H, Nagaoka K, Imakawa K, Sakai S \& Christenson RK 2001 Enhancer regions of ovine interferon-tau gene that confer PMA response or cell type specific transcription. Molecular and Cellular Endocrinology 173 147-155. (doi:10.1016/S0303-7207(00)00408-1)

Yamamoto H, Flannery ML, Kupriyanov S, Pearce J, McKercher SR, Henkel GW, Maki RA, Werb Z \& Oshima RG 1998 Defective trophoblast function in mice with a targeted mutation of Ets2. Genes and Development 12 1315-1326. (doi:10.1101/gad.12.9.1315)

Yang BS, Hauser CA, Henkel G, Colman MS, Van Beveren C, Stacey KJ, Hume DA, Maki RA \& Ostrowski MC 1996 Ras-mediated phosphorylation of a conserved threonine residue enhances the transactivation activities of c-Ets1 and c-Ets2. Molecular and Cellular Biology 16 538-547. (doi:10.1128/MCB.16.2.538)

Received 5 June 2017

First decision 14 July 2017

Revised manuscript received 1 August 2017

Accepted 29 August 2017 